\title{
CONTRIBUIÇÕES DE UM ENCONTRO JUVENIL PARA A ENCULTURAÇÃO CIENTÍFICA
}

\section{Contributions of a juvenile science meeting to science literacy}

\author{
Marcela Fejes $^{1}$ • Eliana Midori Morita ${ }^{2}$. Ana Maria Santos-Gouw ${ }^{3}$ \\ - Isabel Martinelli ${ }^{4}$. Ana Maria Yoshitake ${ }^{5}$
}

Resumo: Este trabalho apresenta a análise de um evento de divulgação científica, organizado, segundo a estrutura usual em congressos, como ação didático-pedagógica voltada para a enculturação científica. Alunos de uma rede pública de Ensino Fundamental II, que participaram de projetos investigativos, foram convidados a divulgar e debater resultados de suas pesquisas em um encontro de investigação científica. Eles também participaram de uma palestra sobre metodologias científicas, meio ambiente e história do município em que vivem. Cada atividade teve como objetivo mobilizar habilidades e conhecimentos específicos da ciência. A vivência nesse tipo de evento possibilitou-lhes perceber que a ciência e a comunicação fazem parte da sociedade e da cultura, pois puderam ouvir, discutir e refletir sobre o processo de trabalho investigativo e seus produtos finais. Como resultado, consideramos que houve vivência de um processo de enculturação científica enriquecido pelas contribuições de diversos atores sociais e instituições.

Palavras-chave: Ensino Fundamental. Evento. Divulgação científica. Projeto de pesquisa. Literacia científica.

\begin{abstract}
This paper presents an analysis of a scientific event organized under the usual structure in Congress, while didactic-pedagogic action focused on literacy in science. Students in a public Middle School, who participated in research projects, were invited to disseminate and discuss results of their research in a meeting about scientific research. They also attended a lecture on scientific methodology, environment and history of the city in which they live. Each activity was designed to mobilize the skills and expertise of science. The experience in this type of event allowed them to realize that science and communication are part of society and culture, because they could hear, discuss and reflect on the work of the investigative process and the outcomes. As a result, we believe that there was experience of a scientific process of enculturation that has been enriched by the contributions of various social actors and institutions.
\end{abstract}

Keywords: Basic education. Event. Science dissemination. Research project. Science literacy.

\footnotetext{
${ }^{1,4}$ Centro de Capacitação e Pesquisa em Meio Ambiente (Cepema), Universidade de São Paulo (USP). Rodovia Conego Rangoni s/n, km 270. Cubatão, SP, Brasil.11.573-000. fejes@cepema.usp.br

${ }^{5}$ Instituto Nacional de Ciência e Tecnologia de Estudos de Meio Ambiente (INCT), Cepema, USP. Cubatão, SP, Brasil.
} 
Fejes, M. et al.

\section{Introdução}

Dentre os conhecimentos construídos pelos homens, a ciência conseguiu, na sociedade moderna, um lugar especial, considerado inatingível pela maior parte da população. Em geral, quando se fala em ciências, forma-se uma imagem na qual se vê, de um lado, o público ignorante e, de outro, os sábios cientistas. No entanto, a ciência pode ser vista como um produto histórico e cultural que atende a interesses ideológicos, econômicos e sociais. Nessa perspectiva, as ciências seriam "como construções de representações sempre ligadas a um contexto e a uma finalidade" (FOUREZ, 2003, p. 120), cuja história baseia-se em uma busca contínua de conhecimentos, marcada por contradições e rupturas, que levam à adoção ou não de novos paradigmas. Aspectos como as descobertas das ciências, suas formas de pensar e suas ideologias interferem na sociedade tanto quanto a sociedade interfere nos rumos da ciência.

Vogt (2006), ao discorrer sobre cultura científica, destaca que o desenvolvimento científico é um processo cultural que pode se apresentar sob três aspectos:

1. Produção e sua difusão entre os pares, a partir da publicação;

2. Processo de ensino-aprendizagem de ciências nos espaços formais de ensino;

3. Divulgação científica na sociedade, de modo a garantir o estabelecimento de uma visão crítica sobre os valores culturais vigentes.

O presente trabalho pretende apresentar e discutir a ocorrência de um evento de enculturação científica chamado "Encontro Juvenil de Investigadores de Ciência", ocorrido em Cubatão, SP, sob o prisma dos dois últimos aspectos destacados por Vogt (2006).

Neste texto, os termos "alfabetização científica" e "enculturação científica" serão utilizados indiscriminadamente. Krasilchik e Marandino (2007), ao utilizarem o termo "alfabetização científica", consideram que a ciência faz parte da cultura e que o público é um sujeito ativo do processo de divulgação, e não um mero receptor de informação. Vogt (2006) apresenta a mesma visão, mas acredita que, ao se falar em cultura científica, deixa-se de enfatizar a questão da aquisição da informação e enfatiza-se a formação de um cidadão atuante. Esse autor considera a expressão "cultura científica" mais ampla, pois engloba tanto a alfabetização científica quanto a popularização e a percepção pública da ciência.

\section{O processo de ensino-aprendizagem de educação científica nas escolas}

Nos espaços formais, a organização curricular obedece a critérios que dependem das finalidades do ensino de ciências. Para Fourez (2003), há, por um lado, uma perspectiva voltada à formação, à inserção e à capacidade criativa do cidadão na sociedade, e, de outro, uma perspectiva que privilegia a formação de especialistas. Segundo esse autor:

Os cursos de ciências que visam à formação de cientistas se ramificam em física, química, biologia. Os que visam à formação cidadã (e talvez a da maioria dos jovens) falam de ambiente, de poluição, de tecnologia, de medicina, de conquista espacial, da história do universo e dos seres vivos etc. São duas orientações diferentes. (FOUREZ, 2003, p. 113) 
Em relação ao processo de ensino-aprendizagem de ciências em si, as práticas pedagógicas também obedecem a critérios e estruturam-se a partir das concepções que se tem sobre o que é aprender, o que é ensinar e o que é ciência. O termo ciência, por exemplo, pode ter diferentes significados: para uns, pode significar processo, um modo de pensar e de adquirir conhecimentos; para outros, pode significar produto, isto é, dados e teorias que resultam de pesquisas; para outros, ainda, o termo pode significar uma instituição que se dedica à pesquisa ou à melhoria da qualidade de vida (KRASILCHIK, 2005).

Se, por exemplo, o professor tiver a concepção de ciência apenas como produto, muito provavelmente ele irá privilegiar sua transmissão aos alunos, embora, conforme ressalta Bizzo (2000, p. 14):

Não se admite mais que o ensino de ciências deva limitar-se a transmitir aos alunos notícias sobre os produtos da ciência. A ciência é muito mais uma postura, uma forma de planejar e coordenar pensamento e ação diante do desconhecido. O ensino de ciências deve proporcionar a todos os estudantes a oportunidade de desenvolver capacidades que nele despertem a inquietação diante do desconhecido, buscando explicações lógicas e razoáveis, amparadas em elementos tangíveis.

Em relação ao que é ensinar e ao que é aprender, sabe-se que o aluno passa por um processo de construção de conhecimento que ocorre por aproximações sucessivas, razão pela qual deveriam ser oportunizadas situações de aprendizagem progressivas nas quais os alunos possam agir sobre o objeto de conhecimento. Carvalho (2005) lembra, também, da necessidade de se criarem espaços onde os alunos aprendam a argumentar cientificamente, a ler, a fazer as respectivas traduções entre as linguagens utilizadas nas ciências e, ainda, a escrever e a ler textos científicos. Espera-se que, ao se deparar com questões de ciência, o aluno possa vê-la como uma forma diferente de pensar e de falar do mundo.

Assim, o processo de ensino-aprendizagem da ciência com essas características seria também um processo de enculturação científica, já que o aluno passa a entender e a participar da cultura científica, vivenciando seus valores, procedimentos e forma de pensar o mundo.

\section{A comunidade/coletividade}

Fourez (2003) aponta que há uma tradição no ensino voltada à educação do indivíduo, ignorando o fato de as pessoas serem seres sociais, que se articulam e se completam. As salas de aula, por exemplo, constroem identidades únicas, porém pode-se dizer que cada uma delas constrói uma cultura compartilhada. Assim:

[...] o sujeito da alfabetização científica não é mais o indivíduo isolado, mas o grupo. Da mesma forma, uma coletividade local pode ser "alfabetizada" em relação à construção de uma indústria poluidora, ou em relação a uma política frente às drogas. Isto significa que foi instaurada nesta comunidade uma cultura (formada de saber, saber-fazer e saber- 
Fejes, M. et al.

ser), permitindo uma discussão pertinente da situação. Nestas condições, um debate democrático torna-se possível. (FOUREZ, 2003, p. 114-115)

Segundo esse autor, para que ocorra o processo de alfabetização científica, é importante que a escola proporcione, aos alunos, a experiência de participação em atos coletivos, como o debate, por exemplo. Para ele, a vivência em experiências coletivas fortalece os indivíduos e a própria coletividade.

\section{A divulgação científica na sociedade}

A divulgação científica pode ter um caráter de educação mais formal ou menos formal. Essa variação depende da intenção dos participantes, do lugar que eles ocupam na sociedade, do espaço onde a educação científica ocorre, do que se pretende que os outros saibam e do tempo disponível.

A conceitualização sobre o que seria educação formal, não formal e informal ainda está em processo de construção. Neste texto, consideramos educação formal como o aprendizado que ocorre de forma sistematizada em instituições de ensino, enquanto a educação informal seria aquela que ocorre de forma espontânea no cotidiano das pessoas, por meio de conversas ou vivências (CHAGAS, 1993). A educação não formal, por sua vez, seria aquela que ocorre, ao longo da vida, fora do ambiente formal de educação (SMITH, 2001), podendo ser veiculada por meio de visitas a museus, acesso a meios de comunicação e a outras instituições promotoras de eventos.

Considera-se que a divulgação científica tem um caráter de educação não formal abrangendo diferentes objetivos relacionados a ciências. $\mathrm{Na}$ área educacional, ela amplia o conhecimento do público leigo em relação ao processo científico e a seus produtos. Na área cívica, a opinião pública informa-se dos impactos do desenvolvimento científico e tecnológico sobre a sociedade. E, na área da mobilização popular, o público participa na formulação de políticas públicas e na escolha de opções tecnológicas (ALBAGLI, 1996).

No entanto, quando se fala em "ensinar ciências", o objetivo não é o de suprir um suposto déficit de informação da população leiga em relação à ciência. Seu papel, segundo Vogt (2008, p. 2), é informar e "atuar de modo a produzir as condições de formação crítica do cidadão em relação à ciência”, ou seja, possibilitar ao cidadão refletir sobre o papel da ciência, sua função na sociedade, as tomadas de decisão que afetam a vida das pessoas, e assim por diante. Para esse autor,

[...] o que está sendo enfatizado não é só a aquisição da informação, a possibilidade de acesso à informação, mas a formação do cidadão no sentido em que ele possa ter opiniões e uma visão crítica de todo o processo envolvido na produção do conhecimento científico com sua circulação e assim por diante. Esse é um conceito relacionado à cultura científica, que modifica os modos de se fazer e pensar a própria divulgação. (VOGT, 2008, p. 2) 
Outro ponto importante em relação à divulgação científica está relacionado à possibilidade de reflexão que pode ser provocada a partir da fala de quem faz ciência. Para Jurdant (2006), um cientista passa a compreender melhor seu próprio saber quando fala dele. Por isso, defende a ideia de que a divulgação deveria ter como objetivo essencial falar ciência, no sentido de haver uma integração na língua comum e estabelecer-se uma relação entre ciência e realidade.

\section{O evento e a enculturação científica}

O $1^{\circ}$ Encontro Juvenil de Investigadores em Ciências de Cubatão consistiu: na participação de alunos de diferentes escolas em discussões sobre o processo de investigação científica ocorrida durante o ano letivo; em uma palestra tematizada sobre a cidade e sobre o processo de trabalho realizado, e, finalmente, em apresentações dos produtos realizados.

Um dos principais objetivos da realização desse evento foi inserir os alunos em um momento de discussão e de construção de participação cidadã numa sociedade tecnológica e científica, ao possibilitar-lhes a vivência em um encontro similar ao vivido pelos cientistas, quando da divulgação de seus trabalhos.

Esta pesquisa pretende investigar se esse encontro pode ser considerado um evento de divulgação científica e em quais aspectos possibilitaria a enculturação científica. Temos como hipótese que o Encontro é um evento cultural de divulgação científica, cujo objetivo é ensinar ciências em um espaço não formal de ensino. As questões que norteiam este trabalho são:

1. A organização do evento possibilitou a reflexão, a escuta e a fala de ciências e do conhecimento dos próprios participantes? A organização tornou significativo o encontro?

2. Quais aprendizagens foram proporcionadas pelo Encontro? Foi possibilitado, aos alunos, refletirem sobre o processo de saber ciência, fazer ciência e falar ciência? Eles puderam compreender o papel das ciências em suas vidas e o papel deles no mundo das ciências e da sociedade? Puderam valorizar o trabalho coletivo?

\section{Organizadores do $1^{\circ}$ Encontro Juvenil de Investigadores em Ciências em Cubatão}

O evento foi organizado por uma equipe do Centro de Capacitação e Pesquisa em Meio Ambiente (Cepema, da Escola Politécnica da Universidade de São Paulo, USP), que pesquisa o uso das tecnologias de informação e comunicação (TIC's) e o trabalho com projetos investigativos ambientais nas escolas de Educação Básica, propondo, para tanto, a implementação de tais projetos nas escolas. Os estudantes de seis escolas públicas de Cubatão participaram de um projeto, desenvolvido pelo Cepema, denominado "Investigações Ambientais na Escola". Tal projeto buscou implementar, nas escolas, quatro projetos de ensino: Projeto Aves, Projeto Agenda 21, Projeto Estação Meteorológica e Projeto Ecologia das Águas. Através deles, os alunos investigaram problemas reais de sua própria comunidade, coletaram dados, trabalharam em grupo e intercambiaram ideias e resultados, enquanto os professores participantes receberam treinamento para usar as ferramentas de comunicação e desenvolver 
Fejes, M. et al.

os conteúdos abordados. Uma equipe de apoio acompanhou o desenvolvimento das atividades do projeto na escola, oferecendo suporte para solução das dúvidas e mediando as atividades desenvolvidas.

O Cepema está localizado no município de Cubatão, SP, e foi construído a partir de um convênio entre a Universidade de São Paulo (USP), a Fundação da Universidade de São Paulo (FUSP), a Companhia de Tecnologia de Saneamento Ambiental do Estado de São Paulo (Cetesb), a Petrobras e o Ministério Público, como parte de um acordo de compensação ambiental da Petrobras em Cubatão.

Assim, o evento foi realizado na sede do Cepema, em Cubatão, e utilizou um auditório, salas de aula e o hall de exposições.

\section{Metodologia}

\section{Os dados coletados, os participantes e o local do evento}

Este estudo foi realizado a partir dos pressupostos da pesquisa qualitativa colocados por Bogdan e Biklen (1994), que apontam algumas características pertinentes a esse tipo de investigação:

- A fonte de dados é o ambiente natural, sendo o investigador o principal instrumento;

- A pesquisa é descritiva;

- O interesse pelo processo é maior do que pelo produto ou resultados;

- A análise dos dados é realizada de forma indutiva;

- O significado é o foco de atenção do pesquisador.

Devido ao pouco espaço físico disponível para receber todos os alunos participantes do projeto "Investigações Ambientais na Escola", as escolas enviaram representantes para discutirem e apresentarem os trabalhos realizados junto ao projeto. Compareceram ao evento, no final de novembro de 2009, 106 alunos, 13 professores e três coordenadores de seis escolas municipais de Ensino Fundamental II de Cubatão, estado de São Paulo.

\section{Cerimônia de abertura}

$\mathrm{O} 1^{\circ}$ Encontro Juvenil de Investigadores em Ciências de Cubatão teve inicio no auditório do Cepema, com uma cerimônia de abertura que contou com a participação dos secretários da Educação e do Meio Ambiente de Cubatão e de vários outros representantes do Governo Municipal e da USP. A fala do Secretário da Educação salientou a importância da pesquisa e da investigação e a necessidade de se "aprender a aprender". Comentou que, por muitos anos, quando estudava na universidade, as pessoas viam com preconceito a sua origem, pois, naquela época, a cidade era conhecida como uma das mais poluídas do mundo. Lembrou, então, da necessidade de os estudantes se orgulharem da cidade por sua beleza natural e por seu histórico de recuperação ambiental. Por fim, salientou o valor dos alunos presentes enquanto protagonistas da história. 


\section{Discussão e reflexão sobre o trabalho realizado durante o ano}

A segunda atividade do dia reuniu, em um bloco, os alunos em salas de aula, monitorados pela equipe de apoio e, em outro, os professores, para discutirem o processo de trabalho anual. Para a análise, foram utilizados registros realizados pelos alunos. Esses registros são narrativas de eventos referentes às investigações realizadas ao longo do ano.

Utilizar tais narrativas como dados de pesquisa tem um caráter interessante, pois aquele que as escreve destaca situações, suprime episódios, reforça influências, nega etapas, lembra e esquece. Para Cunha (1997), o sujeito tem a oportunidade de reconstruir sua experiência de forma reflexiva, ao organizar suas ideias para o relato.

Para escreverem essas narrativas, os estudantes foram organizados da seguinte forma: alunos participantes do mesmo projeto de ensino, provenientes de escolas diferentes, que geralmente não se conheciam, reuniram-se, num primeiro momento, em pequenos grupos (cerca de cinco alunos), para discutirem uma pauta preestabelecida com os seguintes tópicos: atividades realizadas durante o ano; itens aprendidos; dificuldades enfrentadas; uso das ferramentas digitais; elementos de que mais gostaram; sugestões para o próximo ano.

Após as discussões, os grupos registraram por escrito uma síntese de suas ideias. Havia um tempo previamente determinado para o registro e a posterior socialização das opiniões aos demais participantes do evento. Propositalmente, não houve interferência dos professores. Durante esta atividade, os alunos não consultaram suas anotações pessoais, tampouco apostilas. Assim, as narrativas escritas estiveram vinculadas à memória resgatada pelo grupo, o que eles consideraram importante e relevante para o registro.

\section{A palestra}

Em seguida, foi realizada uma palestra na qual se evidenciou o trabalho de investigação realizado durante o ano. A apresentação começou com a questão: "O que tem a ver Cubatão com a Dinamarca?”. A palestrante tratou de pontos como a função da tecnologia na sociedade e sua relação com a ciência, e, aos poucos, abordou os problemas decorrentes da tecnologia, inclusive aqueles enfrentados por Cubatão na década de 1980. Apesar de elogiar a beleza natural da cidade, a palestrante contou histórias e apresentou partes de documentários que ouvia quando jovem: as tragédias da Vila Parisi e da Vila Socó, o condinome dado ao local de "Vale da Morte" e o significado da música "Lua de Mel em Cubatão".

A partir desta contextualização, destacou-se a importância do papel dos alunos enquanto cidadãos, e partes dos trabalhos que eles discutiram ao longo do ano, no fórum online, foram apresentadas como exemplos de atividades científicas.

Por fim, traçando um paralelo com as mensagens postadas pelos alunos no fórum, a palestrante discutiu como ocorre o processo de investigação científica e concluiu sua fala evidenciando o papel dos alunos na história de Cubatão e relacionando esta atividade ao Fórum Ambiental ocorrido em Copenhagen. 
Fejes, M. et al.

\section{Apresentação dos trabalhos dos alunos}

Os trabalhos dos alunos puderam ser conhecidos de duas maneiras: exposição no hall e apresentação oral no auditório. No hall, as escolas expuseram banners, cartazes, livros e imagens realizadas durante o ano letivo. No auditório, os alunos apresentaram seus trabalhos utilizando PowerPoint, filmes e cartazes para ilustrar momentos do trabalho.

\section{Informações complementares}

Informações complementares foram obtidas no decorrer do dia pela equipe de apoio e em relatos e relatórios realizados após o evento. A fim de preservar a identidade dos alunos e das escolas participantes neste trabalho, seus nomes verdadeiros foram substituídos por nomes fictícios. Outras informações foram obtidas mediante entrevistas semiabertas, realizadas com alunos e professores duas semanas após o evento. Além disso, a pauta do encontro foi utilizada como fonte de informação para analisar a organização do evento.

\section{Resultados}

Os dados levantados foram analisados e agrupados em categorias que permitiram responder às questões de pesquisa sobre a organização do evento e as aprendizagens.

\section{Resultado I: a organização do evento}

a) Gestão do tempo

Pela programação da pauta, ficou evidenciada a existência de quatro categorias de atividades dos alunos: a) escuta, b) discussão/reflexão sobre o processo de investigação, c) apresentação de trabalhos e escuta dos trabalhos apresentados, e d) discussão/reflexão sobre os produtos apresentados.

Para compararmos os períodos, optamos por utilizar os minutos como unidade de medida. Conforme se pode observar no Gráfico 1, houve preocupação tanto com o processo quanto com o produto. A apresentação dos trabalhos e discussão dos produtos ocupou, no total, cento e cinquenta minutos; a discussão e reflexão sobre o processo, por sua vez, ocupou cento e vinte minutos.

Gráfico 1. Distribuição das atividades realizadas pelos alunos (em minutos)

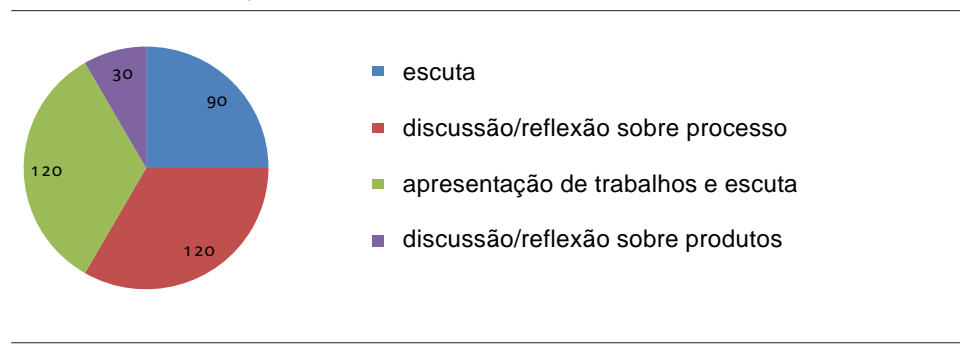

Fonte: Elaborado pelas autoras

776

Ciência $\mathfrak{E}$ Educação, v. 18, n. 4, p. 769-786, 2012 
b) O espaço

A realização do encontro ocorreu em um espaço diferenciado, de design arrojado, mantido por uma das universidades de renome da América Latina. Todo esse aporte fez com que os alunos participantes se sentissem importantes. Uma professora relatou:

"Eu não conhecia o Cepema; o espaço é muito bom. Nossa! E aí alguém falou para mim: 'Ah, professora! Vamos voltar aqui ano que vem. Vamos fazer uns trabalhos aqui ano que vem'. Mas eles gostaram muito dali, né".

Outro professor reiterou a fala anterior ao comentar que tudo o que foi feito poderia ser realizado em outros lugares, mas não como ocorreu no Cepema, pois ali o espaço era diferente. Para ele, o lugar, o palco, o microfone eram diferentes dos outros lugares.

"Acho que essa experiência foi nova para todos os alunos que estavam ali; acho que para todas as escolas. Essas coisas, pode ser que já tenham sido feitas em um lugar ou outro, mas [enfatizou] o lugar, o palco, o microfone, essas coisas assim...”

c) A escuta: personalidades

A presença de personalidades como o Secretário da Educação e do Secretário do Meio Ambiente de Cubatão, de vereadores e de outros representantes de órgãos legais, imprimiu ao encontro um caráter de importância e valorizou a presença dos alunos, que estavam sentados ao lado de pessoas ilustres do governo municipal e da USP.

d) A escuta: palestra

A palestra aguçou a curiosidade dos alunos em relação à história de Cubatão. Uma das pesquisadoras que faz parte da equipe de apoio relatou: 'Umas crianças vieram conversar comigo e me perguntaram como poderiam ver todo o documentário da Vila Socó. Eu disse que a palestrante conseguiu no youtube".

A palestrante, ao contrastar o passado da cidade com a beleza atual, marcou os alunos presentes. Em uma entrevista posterior, um estudante ressaltou a beleza da Serra:

Entrevistadora: "Para quem mora aqui em Cubatão, como é que vocês se sentem sendo moradores da cidade?"

A: "Privilegiado".

B: "É; privilegiado".

C: "Olha, eu não moro aqui em Cubatão, mas venho aqui, pratico esporte, também me sinto privilegiado. É muito bom, porque você tem ar bom para respirar".

D: "Fui até a casa da minha tia e depois a minha tia veio até Cubatão. Ela se encantou com a beleza da Serra". 
Fejes, M. et al.

Esses depoimentos evidenciam que a palestra atingiu seu público-alvo, ao resgatar, também, a história da cidade. Uma professora que chegou após a palestra contou:

"Só participei da tarde. Os alunos falaram muito bem, adoraram. Adoraram a palestrante. Nossa, a hora que eu cheguei, a Elizabete falou, a Elizabete é enfática: "Nossa professora, muito bom! Valeu a espera". [...] É legal colocar o aluno nessa outra maneira de aprender. Ouvir alguém lá na frente. É importante ter uma palestra. E eles adoraram. Eles adoraram, gostaram mesmo, entendeu?"

e) A fala

Além dos momentos dedicados exclusivamente às falas dos alunos (momentos de discussão sobre o processo de trabalho e momentos para apresentação do trabalho realizado), eles também foram chamados a "falar" pela palestrante do encontro. Ela convidou-os a irem para perto do palco e contarem suas dúvidas, ações e impressões.

\section{f) Sugestões}

No momento em que os alunos se reuniram em grupos, ainda no período da manhã, foi feita uma pergunta na qual se pediam sugestões para o próximo ano. Apesar de os alunos ainda não terem visto a palestra, nem apresentado seus trabalhos, das 32 sugestões (Tabela 1), 6 referiam-se à realização de mais encontros no ano seguinte, sendo que 2 delas referiam-se especificamente ao Cepema. Estas respostas foram dadas ainda no início do dia, ou seja, desde cedo os alunos já estavam gostando da experiência de participar do evento.

Tabela 1. Sugestões dadas pelos alunos para se trabalhar no próximo ano

\begin{tabular}{lcc}
\hline \multicolumn{1}{c}{ Sugestões para o próximo ano $(\mathbf{n = 3 2 )}$} & $\mathbf{n}$ & porcentagem \\
\hline ter mais projetos e coisas novas (saúde, solo e ar) & 9 & $28,1 \%$ \\
ter mais encontros & 6 & $18,8 \%$ \\
ter mais pessoas participando & 5 & $15,6 \%$ \\
continuar com os projetos & 4 & $12,5 \%$ \\
apresentar soluções para ambiente e cidade & 2 & $6,3 \%$ \\
ir mais vezes na sala de informática & 1 & $3,1 \%$ \\
Outros & 5 & $15,6 \%$ \\
Total & 32 & $100 \%$ \\
\hline
\end{tabular}

Fonte: Elaborada pelas autoras.

g) Discussão sobre a organização do evento

Conforme observado, a organização do evento conseguiu tornar significativa a realização do encontro para os participantes. Uma das pesquisadoras da equipe de apoio comentou que um estudante, ao ser chamado para ir embora, lamentou que o dia tivesse sido tão curto: "Mas ... já acabou?!". 
A significância do evento deu-se pela organização e pela presença de pessoas ilustres. Os alunos sentiram-se protagonistas de um momento importante em suas formações: participaram de grupos de discussão, apresentaram seus trabalhos a uma comunidade de pesquisadores, ouviram comentários de especialistas e de uma palestrante, além de terem estado em um espaço diferenciado.

Outro aspecto refere-se à realização do evento fora da escola, conferindo-lhe um caráter de educação não formal (SMITH, 2001) e possibilitando, aos alunos, outros tipos de aprendizagem. Em um município como o de Cubatão, desprovido de museus, cinemas e outras formas de lazer, é fundamental proporcionar diferentes espaços culturais para a formação dos cidadãos. A realização do evento vai ao encontro das ideias de Krasilchik e Marandino (2007), que consideram essencial a existência de diferentes espaços destinados ao ensino de ciências.

\title{
Resultado II: as diferentes aprendizagens
}

Durante o encontro, os alunos ouviram, discutiram e apresentaram os trabalhos investigativos realizados no decorrer do ano, o que lhes possibilitou aprendizagens diferenciadas. Eles puderam conhecer e refletir sobre sua história e seu papel na história, participar de outra comunidade que não a escolar e avaliar o trabalho realizado do ponto de vista do processo e do produto apresentado.

a) Valorização de si na valorização da cidade

No primeiro momento, o da cerimônia de abertura, a coordenadora do Projeto Investigações Ambientais na Escola e o secretário de Educação de Cubatão salientaram a importância do trabalho desenvolvido pelos alunos no decorrer do ano. A fala das autoridades provocou, nos alunos, a sensação de estarem fazendo parte de um momento especial. O secretário enfatizou a importância do aprender a aprender, relacionando-o com os projetos de pesquisa, o que fez com que os alunos sentissem que o trabalho realizado durante o ano foi fundamental para suas formações. Ao final, o secretário conclamou-os a valorizarem o município onde nasceram:

\begin{abstract}
"Valorizem a nossa cidade! A nossa cidade não tem praia, mas ela tem serra, tem cachoeira, tem música, tem esporte. É uma cidade valorosa. Então aprendam a valorizar Cubatão. E levem o nome de Cubatão. Cubatão é uma das poucas cidades que está promovendo esse Encontro de Investigação Ambiental. Cubatão é uma cidade que tem uma história de recuperação ambiental, tem ainda umas coisas pra gente fazer. Nós estamos trabalhando para isso e vocês são o futuro da nossa cidade. [...] vocês têm que levar essa esperança de que nós vamos construir uma cidade melhor, porque vocês são o futuro!"
\end{abstract}

A fala das personalidades pareceu ter contagiado os alunos. Já na segunda atividade do dia (discussão do processo de trabalho), ao se categorizarem as respostas à pergunta "O 
Fejes, M. et al.

que vocês aprenderam participando deste projeto?”, em conteúdos conceituais, procedimentais ou de valorização dos recursos naturais e da cidade, percebeu-se que $56 \%$ dos alunos (Gráfico 2) relataram que aprenderam a valorizar os recursos naturais, o meio ambiente e a cidade em que nasceram.

Gráfico 2. O que os alunos mais aprenderam, segundo os próprios alunos.

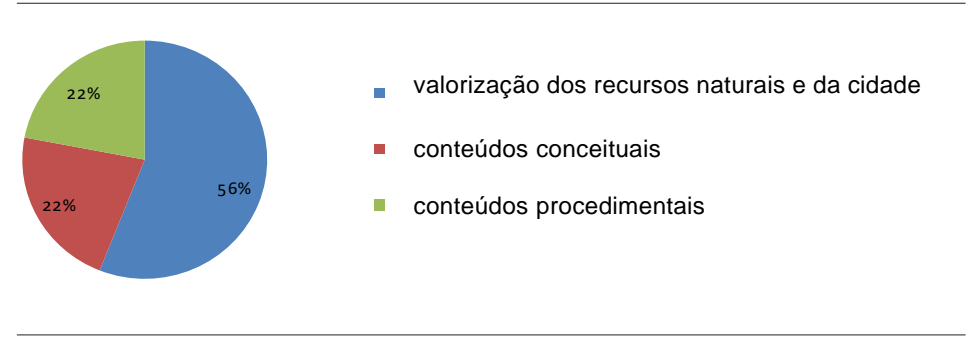

Fonte: Elaborado pelas autoras

$\mathrm{Na}$ atividade seguinte, a palestrante também procurou destacar a importância de Cubatão nas Conferências Mundiais sobre clima e/ou ambiente e o papel dos alunos na luta por um mundo melhor:

"Afinal, Cubatão contribuiu ou não? [para a Conferência sobre Mudança do Clima] Cubatão contribuiu com seus erros e, sobretudo, com as suas mudanças. Hoje, o que eu vi em Cubatão, quando cheguei aqui, é esperança. O que eu vi quando atravessei a Serra do Mar..., eu vi novas árvores, eu quero acreditar que realmente algo possa mudar e obviamente vir a esse local, nesse momento, traz esperança [...]!"

b) Aprender ciência e a fazer ciência

Quando os alunos das diferentes escolas se reuniram em grupos, eles também discutiram sobre o seu processo de trabalho e sobre o que mais gostaram de ter feito. Em relação ao que mais gostaram (Gráfico 3), 68\% destacaram procedimentos como: analisar a água, fazer experiências, trabalhar no campo e observar, entre outros. No gráfico, percebe-se que ainda há alguns alunos que anotaram o espaço do Cepema como um dos preferidos.

Em relação aos procedimentos, alguns alunos destacaram, em seus registros, pontos interessantes:

"Aprendemos coisas que não sabíamos e a utilização de reagentes químicos que nós só víamos na televisão".

"Não tinha que fazer lição, mas trabalhamos muito com o projeto, analisar a água, entrar no site do projeto. A aula ficou diferente, mais legal". 
Gráfico 3. Aspectos de que os alunos mais gostaram no trabalho

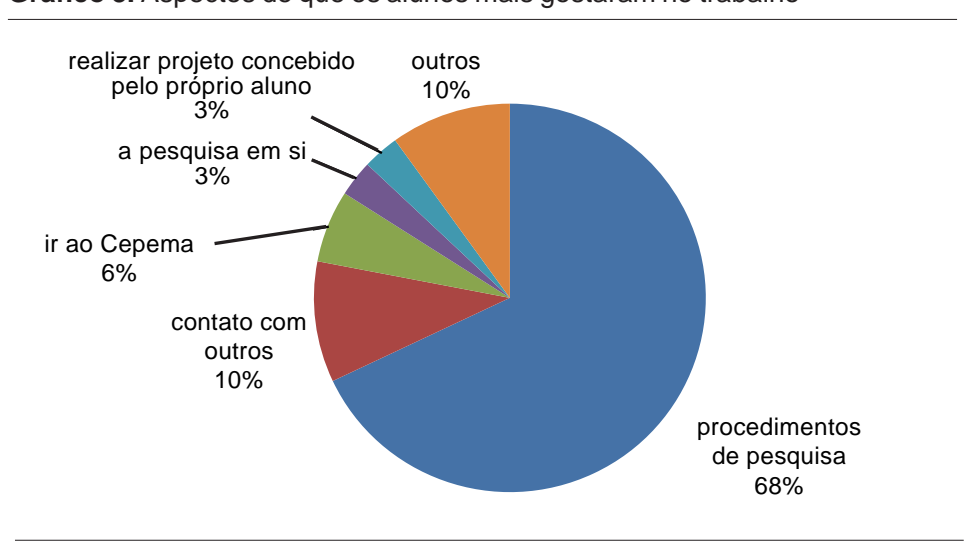

Fonte: Elaborado pelas autoras

"Gostamos muito de trabalhar fora da sala de aula, de usar materiais que nunca tínhamos usado e ter oportunidade de aprender nos divertindo".

Após a discussão coletiva, os alunos voltaram ao auditório e participaram de uma palestra que também tinha como objetivo sistematizar o fazer ciência para e com os alunos. Para conseguir isso, a palestrante recorreu a um fórum on-line, utilizado pelos participantes do projeto durante o ano, para comentar suas respostas e estabelecer relações com as etapas da pesquisa. Para eles, as relações estabelecidas pela palestrante funcionaram como instrumento de avaliação do trabalho e como instrumento de metacognição.

Para explicarmos melhor, transcrevemos parte da apresentação na qual a palestrante projetava a fala de um dos alunos, postada no fórum. $\mathrm{O}$ aluno tinha escrito como estava o tempo no momento em que observava uma ave. A palestrante destacou:

"A maioria das pessoas nem observaria isso. Um aluno observou. Eu não sei se isso vai gerar uma resposta. Eu não sei se isso vai ser importante, mas eu observei. E é bom ficar atento, porque se um animal não come, pode ser que tenha algo estranho."

Pode-se verificar, nesse trecho, a relação estabelecida entre o que o aluno fez e a etapa da pesquisa científica em que se encontrava naquele momento. No trecho a seguir, a palestrante foi além e perguntou se basta "fazer perguntas" para se tornar um cientista.

"Mas vocês podem perceber que essa pessoa fez uma pesquisa. Estão vendo? [e aponta para a tela]. Ela teve que recorrer ao conhecimento de outras pessoas. E agora, o que eu questiono é o seguinte: para ser cientista basta perguntar? Não, não basta se incomodar, olhar o que 
Fejes, M. et al.

está ao seu redor, observar, anotar... Se você parar aí, você é só um curioso. Você não é um cientista. Porque o cientista vai além."

Apesar de a apresentação ser um monólogo, a palestrante criou um suposto diálogo com os alunos. Fez perguntas a si mesma, como se fosse uma aluna, e respondeu-as. A fala destacada a seguir refere-se ao momento em que ela mostrou alguns alunos analisando a água de um corpo hídrico pesquisado durante o projeto.

"O cientista analisa os dados disponíveis por meio de instrumentos tecnológicos, seja ele uma lupa, seja ele extremamente simples, seja ele um computador [...]. Esses cientistas, então, estudam mais, reúnem dados e constroem hipóteses. Vejam, qualquer um é capaz de construir uma hipótese. Por exemplo, a Luciana se atrasou. O que será que aconteceu? Será que a Luciana sofreu um acidente no meio do caminho? [...] São hipóteses, mas não são científicas. E por que não são? Por que é necessário fazer isso daqui. Esta foto mostra: testar as hipóteses."

Nesse instante, apareceu a imagem do comediante americano Jerry Lewis como um cientista maluco. As crianças riram e a palestrante continuou:

“Testar as hipóteses... Você não precisa ser um cientista maluco para fazer isso. Não precisa ser algo completamente absurdo para fazer isso. Nem precisa morrer pela ciência, como fez Marie Curie, que descobriu o elemento rádio [...]."

Como podemos observar, partes do processo de investigação dos alunos foram destacadas para se comentar em qual momento do processo científico eles estavam. Esta estratégia fez com que os alunos refletissem sobre o que fizeram e como pensaram para realizar os procedimentos científicos. Por isso, pode-se dizer que a palestra serviu tanto como instrumento de avaliação de aprendizagem como instrumento de metacognição do aluno.

c) Aprender a falar ciência

Durante o encontro, houve a necessidade de os alunos falarem do processo de investigação e dos resultados de pesquisa. Pela manhã, os alunos de diferentes escolas discutiram sobre o que aprenderam. Um pouco mais tarde, a palestrante também convidou alguns deles a falarem perante todos. No entanto, para falar é necessário posicionar-se, refletir, estar aberto ao debate, à contra-argumentação; é necessário saber do que se fala. Um professor, entrevistado após alguns dias, referiu-se a uma aluna de outra escola:

"Ela foi, ela falava com desenvoltura. Uma pessoa que sabe o que está falando, acredita no que está falando [...]. As melhores falas são exatamente aquelas que são espontâneas, que a pessoa se apropriou do conhecimento."

782

Ciência §̊̊ Educação, v. 18, n. 4, p. 769-786, 2012 
No período da tarde, os alunos apresentaram os produtos realizados, falando sobre os seus e ouvindo sobre os produtos dos outros. A troca de saberes proporcionada pela comunicação favoreceu a aprendizagem e a capacidade de avaliação, como aponta um dos professores:

"O que foi legal lá no encontro foi justamente o que falei, a troca entre as escolas, os alunos verem os trabalhos dos outros, das outras escolas, até viram, entre eles rolou uma comparação, olha só o que eles fizeram, o que é que a gente fez [...] e a apresentação, né? Aquela experiência deles estarem lá, no palco."

Segundo o professor entrevistado, "rolou uma comparação". Não se pode esquecer que comparar exige o estabelecimento de critérios: o que vou comparar? Como julgar o que é melhor ou não? Esta é uma habilidade somente possível quando há produtos a serem comparados. Em geral, nas escolas, a comparação fica resumida ao que fizeram ali dentro e não são possibilitadas novas comparações e, portanto, novas aprendizagens.

\section{Discussão sobre as diferentes aprendizagens}

Conforme se pode verificar nos resultados acima, o trabalho com projetos permitiu que houvesse um início de mudança na perspectiva de ensino, o qual não estava voltado à formação de especialistas e tampouco estava distante dos problemas enfrentados pela sociedade contemporânea. Em relação ao processo de ensino-aprendizagem, os temas tratavam de questões ambientais, de poluição dos corpos hídricos e de tecnologia, entre outros. Lembrando Fourez (2003, p. 113), a perspectiva estava voltada “[...] à formação, à inserção e à capacidade criativa do cidadão na sociedade".

Por outro lado, os temas trabalhados podem ser considerados significativos, pois foram realizados em uma cidade que ficou conhecida mundialmente como uma das mais poluídas do mundo, chamada até mesmo de "Vale da Morte". Tratar de temas ambientais neste município é possibilitar não apenas um resgate histórico, mas também permitir mudanças na maneira de ser das pessoas, tornando-as capazes de compreender o passado para lançarse, de forma mais consciente, ao futuro, possibilidade que foi evidenciada pela palestrante, quando perguntou: “O que Cubatão tem a ver com Copenhagen?”, em alusão à Conferência Climática Mundial que ocorreria alguns dias depois.

Em relação a este aspecto, deve-se destacar a importância das falas do Secretário da Educação e da palestrante, que procuraram fazer a relação entre o passado e o futuro de Cubatão. Também deve ser destacado que o encontro apresentou características de um evento de divulgação científica, conforme o descrito por Albagli (1996), pois ampliou o conhecimento do público leigo em relação ao processo científico e a seus produtos, atuando no sentimento cívico dos participantes, ao retomar sua história e valorizar o sentimento de pertinência.

O encontro também possibilitou, aos alunos, a valorização do processo de autoconhecimento, ao propor que relembrassem aspectos da aprendizagem e que discutissem entre si. As narrativas dos alunos, quando da discussão em grupo, exigiram que eles reconstruíssem suas experiências de forma reflexiva, ampliando suas bases de compreensão, conforme salientado por Cunha (1997). 
Fejes, M. et al.

Comunicar é, portanto, uma forma de aprender; é pela comunicação que aprendemos. Por isso consideramos que a criação de espaços dedicados ao falar dos alunos foi fundamental para suas aprendizagens. Conforme aponta Carvalho (2005), é necessário criar espaços para que os alunos aprendam a argumentar cientificamente, a ler e a estabelecer relações entre as diferentes linguagens utilizadas.

Pelos resultados apresentados, os alunos puderam elaborar uma concepção de que a ciência não é apenas um produto distante de suas realidades. Ela está em suas vidas e pode ocasionar grandes problemas se não for incorporada por eles enquanto uma área de conhecimento cultural. Como disse Bizzo (2000, p. 14), "a ciência é muito mais uma postura, uma forma de planejar e coordenar pensamento e ação diante do desconhecido".

Esses resultados também vão ao encontro da concepção de divulgação científica de Vogt (2008, p. 2), que considera que seu objetivo não é apenas o de informar, mas, também, o de possibilitar que o sujeito possa ter opiniões e "uma visão crítica de todo o processo envolvido na produção do conhecimento científico com sua circulação e assim por diante". Ao "recriar" um evento similar aos vivenciados por cientistas para a divulgação de seus trabalhos em congressos e simpósios, a organização do encontro oportunizou, aos alunos, refletirem sobre a ciência, seu papel na sociedade e a tomada de decisões que podem afetar suas vidas.

\section{Uma aprendizagem especial: a comunidade/coletividade}

$\mathrm{Na}$ sociedade atual, aprender a viver em grupo é uma das necessidades que se impõem. Na entrevista coletiva realizada com alguns alunos após o evento, um deles salientou:

\footnotetext{
"Os pontos positivos foi que a gente conseguiu aprendeu um pouco mais sobre os projetos que a gente tinha, as outras escolas apresentaram as ideias que também tinham e a gente formou quase que um grupo só para poder achar respostas. A gente não aprendeu só nosso projeto, como o de outros projetos que a gente não imaginava que tinha. E, eu não sei, o ponto negativo... Eu não sei se é porque a gente se deu bem... a gente se comunicou... não sei se teve ponto negativo."
}

O que se percebe é que a comunidade na qual viviam foi ampliada, possibilitando novos conhecimentos e amizades. Uma nova identidade comunitária começou a ser construída, conforme se observa no depoimento anterior: “[...] a gente formou quase que um grupo só para poder achar respostas". Houve, nesse caso, um aprendizado coletivo. Como aponta Fourez (2003, p. 114), “o sujeito da alfabetização científica não é mais o indivíduo isolado, mas o grupo".

Não se pode esquecer de que as falas do Secretário de Educação e da palestrante fortaleceram a construção de uma identidade cubatense. Retomando Fourez (2003), podemos dizer que essa coletividade estava sendo "alfabetizada" em relação aos problemas ambientais ocorridos no município e, portanto, nela estava sendo instaurada uma cultura de participação. 


\title{
Considerações finais
}

De certa forma, é fácil argumentar sobre os pontos positivos de um encontro como esse, principalmente em uma cidade desprovida de equipamentos científico-culturais. No entanto, as emoções sentidas pelo professor e seus alunos só foram possíveis porque diferentes instituições uniram-se para a realização de algo diferente, com um caráter festivo e cultural, como aponta um professor:

\begin{abstract}
"O encontro [...], acho que a gente pode ver o que foi realizado nas outras escolas. Às vezes, esses projetos acontecem, mas você não vê o resultado das outras escolas. O que foi feito, como foi trabalhado, inclusive a presença de outros alunos que nós não conhecemos, sempre acaba enriquecendo, né? Sempre aspectos diferentes. Sempre acaba aprendendo... E a empolgação? Os alunos estavam empolgados. [...] É emocionante, a gente nem imaginava, né? Foi bem legal essa parte."
\end{abstract}

Entretanto, o que conferiu ao $1^{\circ}$ Encontro Juvenil de Investigadores de Cubatão seu caráter de divulgação científica foram seus objetivos e, como consequência, sua organização. Houve intenção deliberada para que, conforme aponta Vogt (2008), os alunos pudessem refletir sobre o papel da ciência e sua função na sociedade.

A palestra, as falas das autoridades, as discussões nos grupos e as apresentações dos trabalhos mostraram esta preocupação. São aspectos que permitiram a enculturação científica, pois o público teve participação ativa neste processo. Acreditamos também que o encontro promoveu confrontos de ideias e resultados, possibilitando, a partir disso, "[...] condições de formação crítica do cidadão em relação à ciência" (VOGT, 2008, p. 2).

Ficou evidenciado também que os participantes consideraram ter aprendido "valores", compartilhado ideias (FOUREZ, 2003), refletindo a partir da, e com, a fala (JURDANT, 2006; CARVALHO, 2005). Apesar de os alunos serem estudantes formais do Ensino Fundamental, o evento ocorreu em um espaço não formal, conferindo-lhe a dimensão de um evento de divulgação científica.

Outro aspecto levantado neste encontro refere-se à promoção do sentimento de coletividade, que foi construído tanto no decorrer do ano, nas salas de aula, quanto no próprio evento, ao possibilitar que as escolas se vissem enquanto comunidade escolar e ao possibilitar que todos os participantes se vissem enquanto comunidade cubatense.

Consideramos que a vivência neste tipo de evento possibilitou, aos alunos, perceberem que a ciência e a comunicação fazem parte da sociedade e da cultura, pois puderam discutir e refletir sobre o processo de trabalho e os produtos realizados, além de conhecerem a história do município e compreenderem o valor do trabalho realizado por eles para a sociedade. Nas discussões ocorridas, ficou evidenciado, aos alunos, que cada grupo percorreu diferentes caminhos e que não há verdades absolutas na ciência.

Enfim, consideramos que houve vivência de um processo de enculturação científica, não restrito ao âmbito escolar, mas com contribuições para a inserção cidadã numa sociedade tecnológica-científica e para o meio ambiente, enriquecido pelas contribuições de diversos atores sociais e instituições. 
Fejes, M. et al.

\section{Referências}

ALBAGLI, S. Divulgação científica: informação científica para a cidadania? Ciência da Informação, Brasília, v. 25, n. 3, p. 396-404, set./dez. 1996.

BIZZO, N. Ciências: fácil ou difícil? 2. ed. São Paulo: Ática, 2000.

BOGDAN, R.; BIKLEN, S. Investigação qualitativa em educação: uma introdução à teoria e aos métodos. Porto: Porto Editora, 1994.

CARVALHO, A. M. P. Introduzindo os alunos no universo da ciência. In: WERTHEIN, J.; CUNHA, C. (Org.). Educação científica e desenvolvimento: o que pensam os cientistas. Brasília: Unesco; Instituto Sangari, 2005. p. 61-67.

CHAGAS, I. Aprendizagem não formal/formal das ciências: relações entre museus de ciência e escolas. Revista da Educação, Lisboa, v. 3, n. 1, p. 51-59, 1993.

CUNHA, M. I. Conta-me agora: as narrativas como alternativas pedagógicas na pesquisa e no ensino. Revista da Faculdade de Educação, São Paulo, v. 23, n. 1-2, jan./dez. 1997. Disponível em: <http://www.scielo.br/scielo.php?script=sci_arttext\&pid=S010225551997000100010\&lng=pt\&nrm=iso $>$. Acesso em: 26 abr. 2010.

FOUREZ, G. Crise no ensino de ciências. Investigações em Ensino de Ciências, Porto Alegre, v. 8, n. 2, p. 109-123, ago. 2003.

JURDANT, B. Falar a ciência. In: VOGT, C. (Org.). Cultura científica: desafios. São Paulo: Edusp; FAPESP, 2006. p. 44-55.

KRASILCHIK, M. Ensino de ciências: um ponto de partida para a inclusão. In: WERTHEIN, J.; CUNHA, C. (Org.). Educação científica e desenvolvimento: o que pensam os cientistas. Brasília: Unesco; Instituto Sangari, 2005. p. 169-173.

KRASILCHIK, M.; MARANDINO, M. Ensino de ciências e cidadania. 2. ed. São Paulo: Moderna, 2007.

SMITH, M. K. Non formal education. [S.1.: s.n.], 2001. Disponível em: <http:// www.infed.org/biblio/b-nonfor.htm\#idea>. Acesso em: 15 mar. 2010.

VOGT, C. (Org.) Ciência, comunicação e cultura científica. In: --Cultura científica: desafios. São Paulo: Edusp; Fapesp, 2006. p. 18-26.

VOGT, C. Divulgação e cultura científica. Com Ciencia: Revista Eletrônica de Jornalismo Científico, São Paulo, n. 100, jul. 2008. Disponível em: <http://www.comciencia.br/ comciencia $/$ handler.php?section $=8 \&$ edicao $=37 \& i d=436>$. Acesso em: 03 Jun. 2010.

Artigo recebido em 25/05/2011. Aceito em 17/01/2012. 